\title{
Effects of Laser and Fluoride on the Prevention of Enamel Demineralization: An In Vitro Study
}

\author{
Nastaran Chokhachi Zadeh Moghadam ${ }^{1}$, Bahman Seraj ${ }^{2}$, Nasim Chiniforush ${ }^{3}$, Sara Ghadimi ${ }^{*}$ \\ ${ }^{1}$ University of California Los Angeles - UCLA, School of Dentistry, Department of Hospital Dentistry, Los Angeles, California, \\ USA \\ ${ }^{2}$ Dental Research Center, Dentistry Research Institute and Department of Pediatric Dentistry, School of Dentistry, Tehran \\ University of Medical Sciences, Tehran, Iran \\ ${ }^{3}$ Laser Research Center of Dentistry, Dentistry research Institute, Tehran University of Medical Sciences, Tehran, Iran \\ ${ }^{4}$ Laser Research Center of Dentistry, Dentistry Research Institute and Department of Pediatric Dentistry, School of Dentistry, \\ Tehran University of Medical Sciences, Tehran, Iran
}

\section{*Correspondence to Sara Ghadimi, \\ Department of Pediatric Dentistry, School of Dentistry, Tehran University of Medical Sciences, North Kargar St, AmirAbad St., Tehran, Iran. \\ Tell: +989123187866 \\ Email: sghadimi@tums.ac.ir}

Published online 28 July 2018

\begin{abstract}
Introduction: Investigations have demonstrated that fluoride is an essential element in preventive dentistry. However, there are still controversies about the preventive effects of various kinds of laser. The aim of this study was to examine the effect of diode laser irradiation $(810 \mathrm{~nm})$ with or without fluoride therapy in the prevention of deciduous enamel demineralization.

Methods: Sixty deciduous molar crowns were randomly assigned to 6 groups: C: received no treatment; F: fluoride varnish application; 2L: 2 times diode laser irradiation; 4L: 4 times diode laser irradiation; F2L: 2 times laser irradiation over fluoride varnish; F4L: 4 times laser irradiation over fluoride varnish. Teeth in all groups were subjected to a $\mathrm{pH}$-cycling process to produce artificial caries-like lesions.

Results: The analysis of variance (ANOVA) of microhardness values indicated a significant great effect for laser, fluoride, and the interaction of laser- fluoride on reducing the final microhardness value $(P<0.001)$. However, the $2 \mathrm{~L}$ group was an exception. Despite the $4 \mathrm{~L}$ group, it did not show a significant prevention of enamel microhardness loss $(P=0.125)$. These 2 groups exhibited different effects in the absence of fluoride $\left(P_{2 \mathrm{~L}-4 \mathrm{~L}}=0.05\right)$ while in the presence of the fluoride varnish, no statistically significant difference was observed between them $\left(P_{F 2 L-F 4 L}=0.257\right)$. Moreover, no statistically significant difference was observed between the laser-fluoride combination group and the fluoride group $\left(P_{\mathrm{F} 2 \mathrm{~L}-\mathrm{F}}=0.133, P_{\mathrm{F} 4 \mathrm{~L}-\mathrm{F}}=0.926\right)$.

Conclusion: Our results suggest that fluoride varnish, diode laser, and their combination decrease the loss of the enamel microhardness value and potentially prevent deciduous enamel demineralization. However, the combination of laser and fluoride was not more effective than fluoride.
\end{abstract}

Keywords: Diode laser; Fluoride; Primary tooth; Demineralization.

\section{Introduction}

Although great improvements have been achieved in oral health worldwide, dental caries still persist as a major public health problem, particularly among children. Since treatments are both costly and painful, the prevention rather than the mere treatment of dental caries has become a decisive goal of modern dentistry. ${ }^{1,2}$

There is no doubt that topical fluoride is a considerable element in the prevention of dental caries, and has an effective potential of preventing demineralization and enhancing remineralization..$^{3-5}$ Thereby, professional topical fluoride applications are commonly used to arrest the progression of active dental caries at dental clinics. ${ }^{6}$ The most common forms of the topical fluoride application are dentifrices, mouthwash solutions, gels, and varnishes. ${ }^{7}$ Among these options, fluoride varnish has gained popularity due to its high concentration and safety during application. ${ }^{8}$ However, the preventive effect of topical fluoride depends on its constant presence in the oral cavity and also rely on the patient's oral hygiene. ${ }^{9}$ For young children with a high risk of caries, preventive therapies with less dependence on the patient's compliance would be more effective. Thus, the use of lasers might be a good alternative method for caries prevention, especially in children.

Recently, lasers have been proposed as a supplement to conventional prevention therapies. ${ }^{10}$ They significantly increase the acid resistance of the enamel by decomposition of the organic matrix, carbonate loss, and alteration of crystallinity and permeability of the enamel. ${ }^{11}$ However, 
there are controversies about the effects of different types of lasers on the ultrastructure of the enamel and the best outcome is still unknown.

Many studies have demonstrated the inhibition potential of various lasers on acid-induced dissolution of the enamel, either alone or in combination with fluoride. ${ }^{12,13}$ Some studies have investigated laser-fluoride combination treatment to verify whether the laser could enhance the effect of fluoride on the enamel structure and increase the resistance of the dental structure against acid demineralization. ${ }^{14-17}$ Among various lasers, semiconductor diode lasers with several positive aspects, such as the small size, low cost, and ease of use in the oral cavity, have become quite popular in clinical practice. ${ }^{18}$ However, few reports are found on the caries-preventive effect of diode lasers, with or without fluoride, on the dental enamel, particularly deciduous teeth. ${ }^{17,19,20}$

Although the studies that have been performed to evaluate the preventive effects of lasers have been mostly conducted on permanent teeth, it is considered that there are some differences in the pattern of caries development and prevention between permanent and deciduous teeth. $^{21}$ Deciduous teeth have a fundamental place in mastication, esthetics, development, and stabilization of the stomatognathic system and space maintenance for their permanent successors. ${ }^{22}$ However, higher degrees of porosity along with lower mineral density prone them to demineralization and caries more than permanent teeth. ${ }^{23,24}$

The hypothesis to be tested was that the absorbed 810 $\mathrm{nm}$ wavelength of the diode laser would be efficiently converted into heat, inducing a sufficient temperature rise to reduce the solubility of the mineral and inhibit enamel demineralization.

To be part of a series of studies to elucidate the impact of fluoride and laser on the prevention of human enamel demineralization, the purpose of the present study was to investigate the possibility of reducing the loss of deciduous enamel microhardness after $\mathrm{pH}$ challenges through treating them with diode laser with or without fluoride varnish.

\section{Methods}

Tooth Selection and Grouping

In the present study, 60 human upper and lower deciduous molar teeth (D or E) with caries-free buccal or lingual surfaces were used after obtaining an ethics approval from the Ethical Committee of Tehran University of Medical Sciences. Each tooth was inspected using a light microscope at $\times 10$ magnification, and teeth with no white spots or cracks were selected for the study. The root portion, if present, was sectioned approximately $1 \mathrm{~mm}$ below the cementoenamel junction (CEJ) with a low-speed water-cooled diamond disc. Each tooth was embedded in self-polymerized acrylic resin in a custommade cylindric plastic mold to facilitate handling. They were also polished with 2500 and 3000 grit silicon carbide papers (MATADOR, Germany) to standardize the optical surface properties for the microhardness test. Then, the specimens were coated with 2 layers of an acid resistance nail varnish, leaving one window of approximately $9 \mathrm{~mm}^{2}$ $(3 \times 3 \mathrm{~mm})$ of exposed flat enamel on the buccal or lingual surface.

Then, the specimens were randomly assigned to 6 groups ( $\mathrm{n}=10$ /group): $C$ (control, neither laser nor fluoride treatment); $F$ (Fluoride varnish for 24 hours); $2 L$ (2 times laser irradiation, 20 seconds each irradiation and 60 seconds rest between them); $4 L$ (4 times laser irradiation, 20 seconds each irradiation and 60 seconds rest between them); F2L (2 times laser irradiation over fluoride varnish); F4L (4 times laser irradiation over fluoride varnish) (Figure 1).

\section{Microhardness Analysis}

Prior to any treatment, flat enamel surfaces were tested using the Vickers microhardness test (Bareiss Hardness Tester, Vickers fully automatic hardness tester, Vickers V-Test II, Bareiss Prüfgerätebau GmbH Corp., Germany) to establish their baseline values. The selected test parameter was $50 \mathrm{gr}$ for $20 \mathrm{sec}$, and three indents which were placed at least $100 \mu \mathrm{m}$ apart from each other. This condition was similar for all samples.

\section{Fluoride Treatment}

In the $\mathrm{F}$ group, $5 \%$ fluoride varnish (DuraShield ${ }^{\circledR}, 5 \%$ sodium fluoride varnish, sultan Corp, USA) was applied with a micro brush on the dried enamel surface. Teeth coated with fluoride varnish were immersed in separate bottles of normal saline serum for a period of 24 hours. After 24 hours of contact with the tooth surface, the fluoride varnish was wiped off the enamel surface using a sterile gauze and low-speed brush to simulate the removal of tooth brushing.

\section{Laser Treatment}

The specimens in the $2 \mathrm{~L}$ and $4 \mathrm{~L}$ groups were subjected to 2 times and 4 times radiation with a GaAlAs diode laser (CHEESE $^{\mathrm{TM}}$, GIGAA, China), respectively. The following parameters were used: $810 \mathrm{~nm}$ wavelength, $2 \mathrm{~W}$ output power, $80 \mathrm{~J}$ energy (for 2 times irradiation) and $160 \mathrm{~J}$ energy (for 4 times irradiation), 40 seconds and 80 seconds irradiation time, 60 seconds rest between irradiations, energy density of $444.5 \mathrm{~J} / \mathrm{cm}^{2}$ per irradiation, $400 \mu \mathrm{m}$ tip diameter in continuous wave (CW) laser source and sweeping motion. The laser beam was irradiated over 1 $\mathrm{mm}$ of the samples and maintained the same distance at all times.

\section{Combined Laser-Fluoride Treatment}

The specimens in the combined treatment groups (F2L and F4L) were subjected to 2 (F2L) or 4 times (F4L) laser irradiation over the fluoride varnish immediately after 


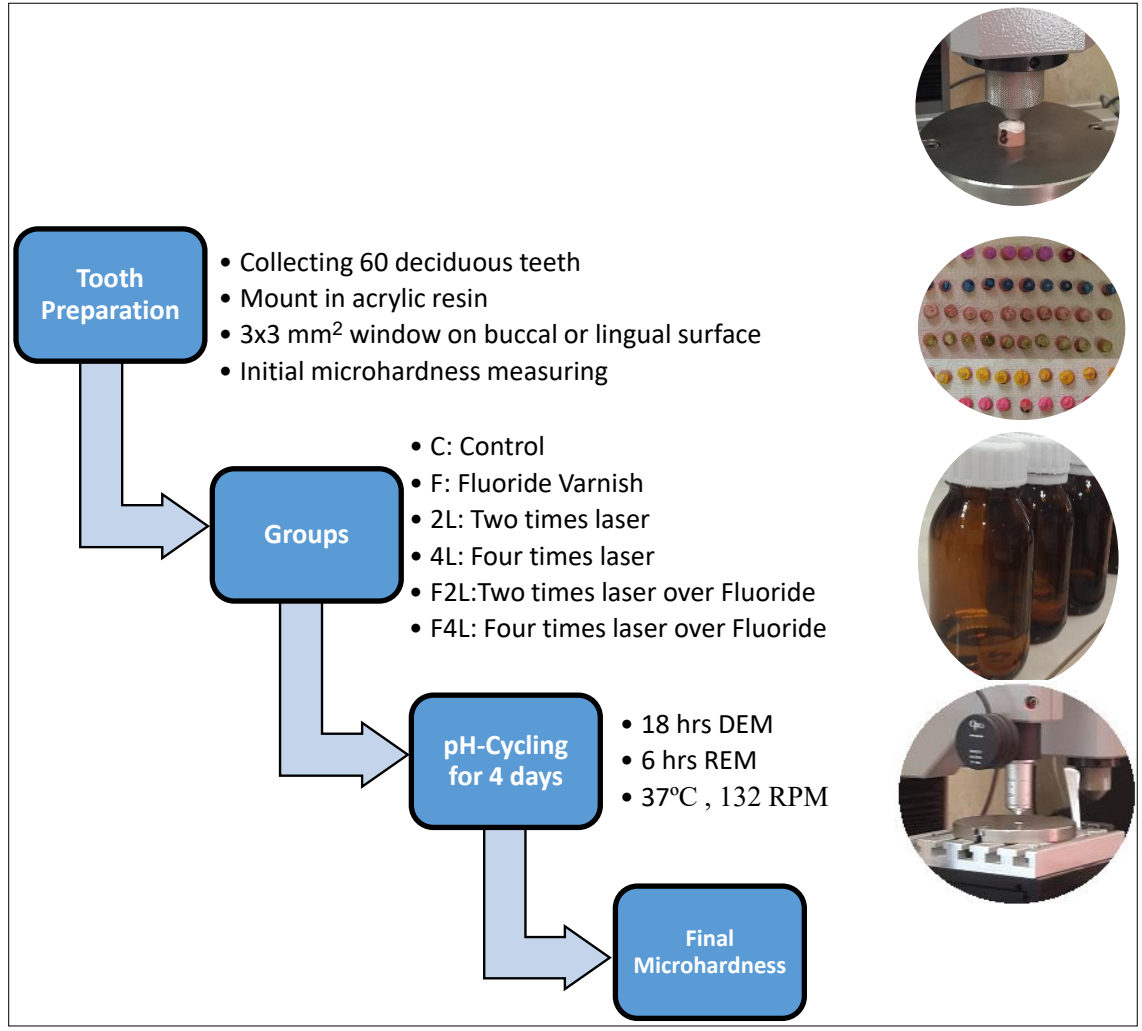

Figure 1. Flowchart of the Study Experimental Design.

application of the fluoride varnish on the tooth surface. The laser beam overcast the fluoride varnish and touched the samples at a standard distance of $1 \mathrm{~mm}$. After laser irradiation, the fluoride varnish remained on the enamel surface for 24 hours and specimens were placed separately in bottles containing normal saline. Fluoride varnish was then wiped off with sterile gauze and tooth brushing. In all treatment groups, the same diode laser parameters and fluoride varnish were used.

\section{$\mathrm{pH}-\mathrm{Cycling}$ Process}

A 4-day $\mathrm{pH}$-cycling scheme, including 18 hours in a demineralizing (DEM) solution and 6 hours in a remineralizing (REM) solution, was properly performed to form artificial caries-like lesions in all 6 groups. ${ }^{25}$

The demineralizing solution, with a $\mathrm{pH}$ of 4.6 , contained $0.05 \mathrm{M}$ acetic acid, $2.2 \mathrm{mM}$ calcium, and $2.2 \mathrm{mM}$ phosphate ions. The remineralizing solution, with a $\mathrm{pH}$ of 7.0, contained $0.15 \mathrm{M}$ potassium chloride, $1.5 \mathrm{mM}$ calcium, and $0.9 \mathrm{mM}$ phosphate ions. The $\mathrm{pH}$-cycling process started with the demineralizing phase. Each sample was immersed individually in $15 \mathrm{~mL}$ of the deremineralization solution and continuously stirred at a speed of 132 RPM by a shaker incubator at $37^{\circ} \mathrm{C}$ in a particular glass bottle. ${ }^{26}$

After each phase, irrigation with distilled water was done for 15 minutes using an ultrasound cleaner device and the samples were then dried. The $\mathrm{pH}$-cycling regime was repeated for three days and nights of alternating DEM and REM cycles as described above, with no further intervention. At the end of the process, the samples were kept in distilled water until the final microhardness test was performed.

Finally, the samples were again analyzed using the same parameters of the Vicker's microhardness test. The investigator was totally blind to the subject or group the samples belonged to.

\section{Statistical Analysis}

The mean microhardness value of each tooth at baseline and a/1t final measurements were calculated. An analysis of variance (ANOVA) was used for the assessment of the effect(s) of laser and fluoride treatment and their potential statistical interaction.

The Levene test was carried out to check the effect of fluoride in groups. Subsequently, the Tukey multiple comparison test was applied to compare the effect of three subsets of laser treatment individually (no irradiation, 2 times irradiation, 4 times irradiation) with or without fluoride treatment. The results are presented as mean \pm standard deviation (SD). A $P$ value of less than 0.05 was considered statistically significant.

\section{Results}

In this study, all samples had an initial microhardness value of about $300-450 \mathrm{VHN}$. Therefore, there were no 
statistically significant differences among the initial microhardness values of the groups prior to any treatment or $\mathrm{pH}$ cycling $(P>0.05)$.

The smallest microhardness reduction after $\mathrm{pH}$-cycling was observed in the $4 \mathrm{~L}$ (181.39), F (196.09) and F4L (218.9) groups. The highest microhardness reduction was recorded in the C (371.5), 2L (252.7), and F2L (250.82) groups (Table 1, Figure 2).

Table 2 shows the result of ANOVA, generally indicating the significant effect of laser $(P=0.008)$, fluoride $(P<0.001)$, and their interaction $(P=0.003)$ on final microhardness after $\mathrm{pH}$-cycling.

To be more specific, data analysis revealed the overwhelming effectiveness of all treatments in preventing enamel demineralization, except the 2 times laser therapy $(P=0.125)$.

The result obtained from Levene $t$ test also showed that fluoride had no significant positive impact on the preventive ability of the laser (Figure 3), Indeed, there was no statistically significant difference between combined laser- fluoride and laser groups $(P=0.793)$.

There was a significant difference between $2 \mathrm{~L}$ and $4 \mathrm{~L}$ groups $(P=0.048)$.

There were no significant differences between F-F2L $(P=0.133)$, F-F4L $(P=0.926)$, and F2L-F4L $(P=0.257)$ groups. In other words, in the presence of fluoride, significant differences were not seen between groups

Table 1. Means and Standard Deviation (SD) of Initial and Final Enamel Microhardness for Each Group

\begin{tabular}{lccc}
\hline Groups & $\begin{array}{c}\text { Initial Microhardness } \\
\pm \text { SD }\end{array}$ & $\begin{array}{c}\text { Final Microhardness } \\
\pm \text { SD }\end{array}$ & Difference \\
\hline C & $411.4 \pm 40.80$ & $39.9 \pm 19.99$ & 371.5 \\
2L & $343.2 \pm 90.25$ & $90.5 \pm 61.74$ & 252.7 \\
4L & $335.44 \pm 118.46$ & $154.05 \pm 68.34$ & 181.39 \\
F & $367.22 \pm 40.88$ & $171.13 \pm 74.03$ & 196.09 \\
F2L & $370.42 \pm 48.12$ & $119.60 \pm 48.32$ & 250.82 \\
F4L & $380.17 \pm 44.66$ & $161.27 \pm 41.45$ & 218.9 \\
\hline
\end{tabular}

C (control); F (Fluoride varnish); 2L (2 times laser irradiations); 4L (4 times laser irradiations); F2L (2 times laser irradiation over fluoride varnish); F4L (4 times laser irradiation over fluoride varnish).

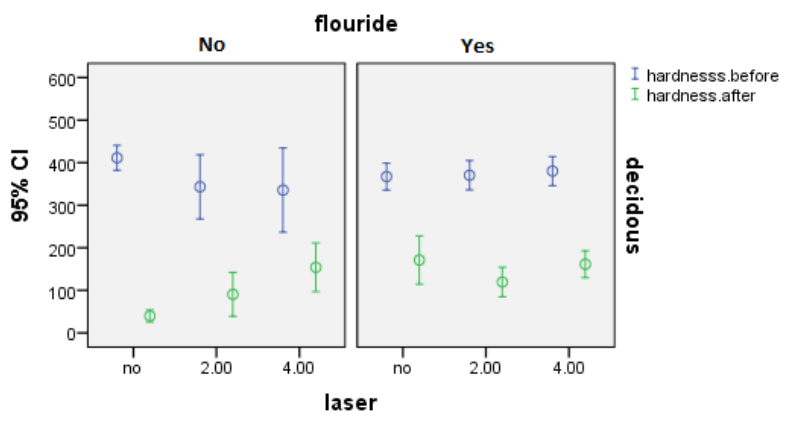

Figure 2. Error Bar of Means of Initial and Final Microhardness Values and $95 \%$ Cls of Them. treated with laser and groups without laser therapy, as well as between various times of laser irradiation.

\section{Discussion}

It is believed that various types of lasers under appropriate irradiation parameters can cause a number of structural and physicochemical changes that offer cariostatic features. Some of these changes involve purifying the enamel hydroxyapatite via decreasing carbonate and crystalline water, ${ }^{27,28}$ reducing the enamel permeability via changing the enamel surface morphology to a melted and resolidified one, ${ }^{29}$ increasing the fluoride deposition on enamel surfaces, ${ }^{15}$ and inducing the formation of fluorapatite which is more resistant to acid demineralization than apatite with carbonate or hydroxyl ions. ${ }^{30,31}$

There are hardly any studies on the effects of the diode laser on the dental structure, especially using enamel microhardness. Indeed, to the best of our knowledge, only four previous studies investigated the effect of the diode laser on deciduous teeth ${ }^{17,19,20,32}$ and only one of them studied the enamel microhardness changes either with or without fluoride application. ${ }^{19}$ Thus, the effect of the diode laser on the ultrastructure of the enamel and its ability to reduce enamel microhardness loss after acid challenge is still controversial. No data has been published

Table 2. Sum of Squares, Mean Square and $P$ Value of Final Enamel Microhardness Values for 2 Independent Variables and Their Interactions.

\begin{tabular}{llllll}
\hline Source & $\begin{array}{l}\text { Sum of } \\
\text { Squares }\end{array}$ & $\boldsymbol{d f}$ & $\begin{array}{l}\text { Mean } \\
\text { Square }\end{array}$ & $\boldsymbol{F}$ & $\boldsymbol{P}$ \\
\hline Laser & 31807.154 & 2 & 15903.577 & 5.392 & 0.008 \\
Fluoride & 41776.392 & 1 & 41776.392 & 14.163 & $<0.001$ \\
Laser x fluoride & 40044.520 & 2 & 20022.260 & 6.788 & 0.003 \\
\hline
\end{tabular}

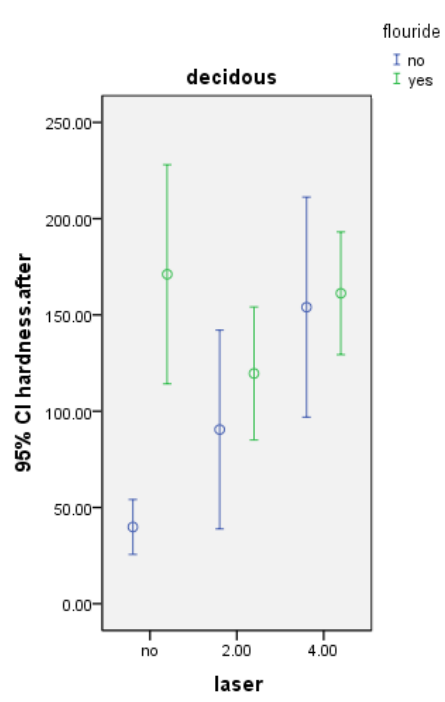

Figure 3. Error Bar of Means of Final Microhardness Values and $95 \%$ Cls of it. 
yet on the different irradiation times of diode laser as well. In this study, we found that 2 times laser irradiation had no significant effect on the suppression of the enamel microhardness reduction, which is in contrast to the results of 4 times irradiation in our study and 2 previous studies by Souza et al ${ }^{32}$ and da Silva Barbosa et al. ${ }^{19}$ Souza et $\mathrm{al}^{32}$ studied the effects of the CO2, Nd:YAG and diode lasers with $1.0 \mathrm{~W}$ power and $84.9 \mathrm{~J} / \mathrm{cm}^{3}$ energy on the enamel of deciduous human teeth via scanning electron microscope. They showed the formation of a melted and evenly resolidified enamel surface, suggesting an increase in the resistance of the dental enamel against acids. Thus, they demonstrated that laser could possibly play an important role in the prevention of dental caries without considering any topical fluoride treatment. A study by da Silva Barbosa et $\mathrm{al}^{19}$ is the only investigation that considered microhardness changes (Knoop) in deciduous teeth and compared the groups treated with fluoride and diode laser $\left(810 \mathrm{~nm}, 100 \mathrm{~mW} / \mathrm{cm}^{2}, 4.47 \mathrm{~J} / \mathrm{cm}^{2}\right.$ and $\left.9 \mathrm{~J}\right)$. They showed that the smallest microhardness reduction belonged to the combined laser-fluorinated cream followed by laser-non-fluorinated cream and laser alone groups. ${ }^{19}$ Santaella et $\mathrm{al}^{17}$ evaluated the lesion depth after $\mathrm{pH}$-cycling through polarized light microscopy and compared the caries prevention potential of the diode laser $(809 \mathrm{~nm}, 140 \mathrm{~mJ})$ with topical fluoride on primary enamel teeth. In contrast, they found a lower preventive potential of laser application in comparison with fluoride. ${ }^{17}$

The finding that there is no significant difference between 4 times laser and its combination with fluoride varnish is in agreement with the results of the studies conducted by da Silva Barbosa et al ${ }^{19}$ and De Sant'Anna et al. ${ }^{20}$

De Sant'Anna et $\mathrm{al}^{20}$ observed the conservation of calcium and phosphorus in the elemental weight of the irradiated deciduous enamel using diode laser $(810 \mathrm{~nm}, 100 \mathrm{~mW} /$ $\mathrm{cm}^{2}, 4.47 \mathrm{~J} / \mathrm{cm}^{2}, 9 \mathrm{~J}$ ) with or without fluorinated cream. They demonstrated that combination treatment offered not greater impact than laser therapy. ${ }^{20}$

Our results also showed no significant differences between F, F2L and F4L groups, indicating that the effect of fluoride was considerable and similar to its combination with laser. Hence, laser irradiation had no synergistic effect on the fluoride varnish. The additional application of laser on fluoride did not cause a significant increase or decrease in enamel microhardness changes. Also, different times of laser irradiation in the presence of fluoride varnish had no different effects as well. On the one hand, this finding is similar to the results of a study by Santaella et $\mathrm{al},{ }^{17}$ that showed no difference between groups treated with fluoride and groups that received fluoride and laser in deciduous teeth. On the other hand, this part of our findings is in contrast with the results reported by da Silva Barbosa et $\mathrm{al}^{19}$, stating approximately similar high surface microhardness loss percentages in the control, fluoridated cream, and non-fluoridated cream treated groups. Thus, they suggested that the combination of laser and fluoridated cream resulted in less surface microhardness loss than fluoridated cream alone.

Differences between our results and previous studies may partially be explained by different laser parameters and study conditions. For example, in the prior studies, low-power diode lasers with different parameters were commonly used, some of them used photo-absorber creams, most of them considered different features of the enamel except microhardness, and $\mathrm{pH}$-cycling schemes were mostly different from our study.

Considering these controversies, further studies on different effects of diode laser on deciduous enamel microhardness are warranted.

\section{Conclusion}

In this study, enamel microhardness was investigated in the deciduous dentition treated with diode laser for 2 or 4 times (809 nm, $2 \mathrm{~W}, 40 \mathrm{~J}$ ) alone or in combination with fluoride varnish. Although laser and fluoride treatments reduced the enamel microhardness loss and enamel demineralization after $\mathrm{pH}$-cycling, the combination of laser and fluoride was not more effective than fluoride treatment alone. Moreover, there was no difference between the results of 2 or four times of laser irradiation in the presence of fluoride.

\section{Ethical Considerations}

Our study was approved by the Ethical Committee of Tehran University of Medical Sciences (\#92-03-97-2409).

\section{Conflict of Interests}

The authors declare no conflict of interest.

\section{Acknowledgment}

This article is part of a graduate thesis by Nastaran Chokhachi Zadeh Moghadam that was carried out in 2014 at the Dental School of Tehran University of Medical Sciences under the advisory guidance of Dr. Sara Ghadimi and Dr. Bahman Seraj. We have to express our appreciation to Dr. Mohammad Javad Kharazi Fard, and Dr. Reza Fekrazad who provided expertise that greatly assisted the research.

This work was supported by Tehran University of Medical Sciences [grant number 92-03-97-24090].

\section{References}

1. Petersen PE. The World Oral Health Report 2003: continuous improvement of oral health in the 21 st century-the approach of the WHO Global Oral Health Programme. Community Dent Oral Epidemiol. 2003;31 Suppl 1:3-23.

2. Hugo FN, Vale GC, Ccahuana-Vasquez RA, Cypriano $S$, de Sousa Mda L. Polarization of dental caries among individuals aged 15 to 18 years. J Appl Oral Sci. 2007;15(4):253-258.

3. Hardwick K, Barmes D, Writer S, Richardson LM. International collaborative research on fluoride. J Dent Res. 2000;79(4):893-904. doi:10.1177/00220345000790040301 
4. Marinelli CB, Donly KJ, Wefel JS, Jakobsen JR, Denehy GE. An in vitro comparison of three fluoride regimens on enamel remineralization. Caries Res. 1997;31(6):418-422. doi:10.1159/000262432

5. Maguire A. ADA clinical recommendations on topical fluoride for caries prevention. Evid Based Dent. 2014;15(2):38-39. doi:10.1038/sj.ebd.6401019

6. Pandit S, Kim JE, Jung KH, Chang KW, Jeon JG. Effect of sodium fluoride on the virulence factors and composition of Streptococcus mutans biofilms. Arch Oral Biol. 2011;56(7):643-649. doi:10.1016/j.archoralbio.2010.12.012

7. Professionally applied topical fluoride: evidencebased clinical recommendations. J Am Dent Assoc. 2006;137(8):1151-1159.

8. Carey CM. Focus on fluorides: update on the use of fluoride for the prevention of dental caries. J Evid Based Dent Pract. 2014;14 Suppl:95-102. doi:10.1016/j.jebdp.2014.02.004

9. Featherstone JD. Delivery challenges for fluoride, chlorhexidine and xylitol. BMC Oral Health. 2006;6 Suppl 1:S8. doi:10.1186/1472-6831-6-s1-s8

10. Esteves-Oliveira M, Zezell DM, Meister J, et al. CO2 Laser (10.6 microm) parameters for caries prevention in dental enamel. Caries Res. 2009;43(4):261-268. doi:10.1159/000217858

11. Ana PA, Bachmann L, Zezell DM. Lasers effects on enamel for caries prevention. Laser Phys. 2006;16(5):865-875. doi:10.1134/s1054660x06050197

12. Korytnicki D, Mayer MP, Daronch M, Singer Jda M, Grande $\mathrm{RH}$. Effects of Nd:YAG laser on enamel microhardness and dental plaque composition: an in situ study. Photomed Laser Surg. 2006;24(1):59-63. doi:10.1089/pho.2006.24.59

13. Can AM, Darling CL, Ho C, Fried D. Non-destructive assessment of inhibition of demineralization in dental enamel irradiated by a lambda $=9.3$-microm $\mathrm{CO} 2$ laser at ablative irradiation intensities with PS-OCT. Lasers Surg Med. 2008;40(5):342-349. doi:10.1002/lsm.20633

14. Zancope BR, Rodrigues LP, Parisotto TM, SteinerOliveira C, Rodrigues LK, Nobre-dos-Santos M. CO2 laser irradiation enhances $\mathrm{CaF} 2$ formation and inhibits lesion progression on demineralized dental enamel-in vitro study. Lasers Med Sci. 2016;31(3):539-547. doi:10.1007/s10103016-1900-4

15. Vitale MC, Zaffe D, Botticell AR, Caprioglio C. Diode laser irradiation and fluoride uptake in human teeth. Eur Arch Paediatr Dent. 2011;12(2):90-92.

16. Gonzalez-Rodriguez A, de Dios Lopez-Gonzalez J, del Castillo Jde D, Villalba-Moreno J. Comparison of effects of diode laser and $\mathrm{CO} 2$ laser on human teeth and their usefulness in topical fluoridation. Lasers Med Sci. 2011;26(3):317-324. doi:10.1007/s10103-010-0784-y

17. Santaella MR, Braun A, Matson E, Frentzen M. Effect of diode laser and fluoride varnish on initial surface demineralization of primary dentition enamel: an in vitro study. Int J Paediatr Dent. 2004;14(3):199-203. doi:10.1111/ j.1365-263X.2004.00550.x

18. Klim JD, Fox DB, Coluzzi DJ, Neckel CP, Swick MD. The diode laser in dentistry. Rev Wavelengths. 2000;8:13-6.
19. da Silva Barbosa P, da Ana PA, Poiate IA, Zezell DM, de Sant' Anna GR. Dental enamel irradiated with a lowintensity infrared laser and photoabsorbing cream: a study of microhardness, surface, and pulp temperature. Photomed Laser Surg. 2013;31(9):439-446. doi:10.1089/ pho.2013.3485

20. de Sant'Anna GR, dos Santos EA, Soares LE, et al. Dental enamel irradiated with infrared diode laser and photoabsorbing cream: part 2--EDX study. Photomed Laser Surg. 2009;27(5):771-782. doi:10.1089/pho.2008.2401

21. De Menezes Oliveira MA, Torres CP, Gomes-Silva JM, et al. Microstructure and mineral composition of dental enamel of permanent and deciduous teeth. Microsc Res Tech. 2010;73(5):572-577. doi:10.1002/jemt.20796

22. Dean JA. McDonald and Avery's Dentistry for the Child and Adolescent. 10th ed. Elsevier, Health Sciences Division; 2016.

23. Wang LJ, Tang R, Bonstein T, Bush P, Nancollas GH. Enamel demineralization in primary and permanent teeth. J Dent Res. 2006;85(4):359-363. doi:10.1177/154405910608500415

24. Azevedo DT, Faraoni-Romano JJ, Derceli Jdos R, PalmaDibb RG. Effect of Nd:YAG laser combined with fluoride on the prevention of primary tooth enamel demineralization. Braz Dent J. 2012;23(2):104-109.

25. Liu JF, Liu Y, Stephen HC. Optimal Er:YAG laser energy for preventing enamel demineralization. J Dent. 2006;34(1):6266. doi:10.1016/j.jdent.2005.03.005

26. Hsu CY, Jordan TH, Dederich DN, Wefel JS. Laser-matrixfluoride effects on enamel demineralization. J Dent Res. 2001;80(9):1797-1801. doi:10.1177/002203450108000905 01

27. Correa-Afonso AM, Bachmann L, de Almeida CG, Dibb RG, Borsatto MC. Loss of structural water and carbonate of Nd:YAG laser-irradiated human enamel. Lasers Med Sci. 2015;30(4):1183-1187. doi:10.1007/s10103-014-1532-5

28. Correa-Afonso AM, Bachmann L, Almeida CG, Corona SA, Borsatto MC. FTIR and SEM analysis of CO2 laser irradiated human enamel. Arch Oral Biol. 2012;57(9):11531158. doi:10.1016/j.archoralbio.2012.02.004

29. Ying D, Chuah GK, Hsu CY. Effect of Er:YAG laser and organic matrix on porosity changes in human enamel. $J$ Dent. 2004;32(1):41-46.

30. Zancope BR, Cesar MM, Rodrigues LK, Nobre-DosSantos M. Evaluation of the effect of a $\mathrm{CO} 2$ laser and fluoride on the reduction of carious lesions progression in primary teeth: an in vitro study. Proc SPIE Int Soc Opt Eng. 2014;8929:89290K. doi:10.1117/12.2037284

31. Hsu CY, Jordan TH, Dederich DN, Wefel JS. Effects of low-energy CO2 laser irradiation and the organic matrix on inhibition of enamel demineralization. J Dent Res. 2000;79(9):1725-1730. doi:10.1177/002203450007900914 01

32. Souza MR, Watanabe IS, Azevedo LH, Tanji EY. Morphological alterations of the surfaces of enamel and dentin of deciduous teeth irradiated with Nd:YAG, CO2 and diode lasers. Int $J$ Morphol. 2009;27(2):441-446. doi:10.4067/S0717-95022009000200021 